\title{
NATURAL CONVECTION OF A NANOFLUID IN A CONICAL CONTAINER
}

\author{
B.Mahfoud ${ }^{1, *}$, A. Bendjaghloli2
}

\begin{abstract}
Natural convection is simulated in a truncated cone filled with $\mathrm{Cu}$-water nanofluid, pure water is considered as the base fluid with $\operatorname{Pr}=6.2$ and $(\mathrm{Cu})$ is the nanoparticle . Inclined and top walls have constant temperature where the heat source is located on the bottom wall of the conical container which is thermally insulated. A finite volume approach is used to solve the governing equations using the SIMPLE algorithm for different parameters such as Rayleigh number $\left(10^{3}, 10^{4}, 10^{5}\right.$ and $\left.10^{6}\right)$, inclination angle of inclined walls of the enclosure and heat source length $(0.3 \mathrm{~L}, 0.7 \mathrm{~L}$ and $\mathrm{L})$. The results showed an enhancement in cooling system by using a nanofluid, when conduction regime is assisted. The inclination angle of inclined sidewall and heat source length affect the heat transfer rate and the maximum temperature.
\end{abstract}

\section{Keywords: Heat Source, Truncated Cone, Nanofluid, Natural Convection}

\section{INTRODUCTION}

The numerical study reported here concerned the flows produced in truncated conical containers filled with a water-based nanofluid containing Copper $(\mathrm{Cu})$. The two parameters required to characterize the problem are the Rayliegh number Ra, and the slope angle of the inclined wall, $\alpha$. This problem may be encountered in a number of electronic cooling devices equipped with nanofluids. The resulting mixture of the base fluid and nanoparticles having unique physical and chemical properties is referred to as a nanofluid. It is expected that the presence of the nanoparticles in the nanofluid increases the thermal conductivity and therefore substantially enhances the heat transfer characteristics of the nanofluid. Differentially heated enclosures are extensively used to simulate natural convection heat transfer within systems using nanofluids [1-2]. Recently, Oztop and Abu-Nada [3] numerically studied heat transfer and fluid flow due to buoyancy forces in a partially heated enclosure using nanofluids made with different types of nanoparticles. They argued that the heat transfer enhancement was more pronounced at low aspect ratios than at high aspect ratios of the enclosure. They found that for all Rayleigh numbers, the mean Nusselt number increased as the volume fraction of nanoparticles increased. Aminossadati and Ghasemi [4] presented a numerical study of natural convection cooling of a heat source embedded on the bottom wall of an enclosure filled with nanofluids. They results indicate that adding nanoparticles into pure water improves its cooling performance especially at low Rayleigh numbers. The type of nanoparticles and the length and location of the heat source proved to significantly affect the heat source maximum temperature. Different types of enclosures under localized heating have been studied extensively by many authors. Ben-Mansour and Habib [5] studied the natural cooling of a rectangular cavity filled with $\mathrm{Cu} /$ water nanofluids. They found that the heat transfer coefficient in the vicinity of left wall decreases from the bottom to top of the wall. They also observed the increase of heat transfer rate with increasing the solid volume fraction.

The problem of steady free convection heat transfer of a right angle triangular enclosure filled with a porous medium and saturated by a nanofluid was numerically investigated by Sun and Pop [6]. For the enclosure, the heat source is located on the vertical wall, the inclined wall is coldwith a fixed temperature and the vertical wall is adiabatic respectively. They found that, Nusselt number attained a maximum value with both highest Ra number and largest heater size. Heat transfer within the cavity is enhanced decreasing the enclosure aspect ratio and lowering the heat source. In addition, $\mathrm{Cu}$ based nanofluid appeared as the better nanofluid for heat transfer.

Garoosi et al. [7] studied the influence of several pairs of heaters and coolers (HACs) on the natural convection of water-based nanofluids inside a 2D square cavity. They showed that heat transfer rate is mainly governed by HAC position and surface area. Increasing the number of HAC is also better than increasing the HAC size. Well vertically oriented rectangular HAC also increases the heat transfer rate in comparison to horizontal rectangular and square HAC. Finally, the optimum value of volume fraction in heat transfer enhancement is 
reported to be $1 \%$ for all tested nanoparticles. Hiris and al. [8] experimentally investigated the natural convection of nanofluids within a 3D cubic enclosure under the influence of cavity inclination. In this configuration, two opposite surfaces are respectively hot and cold, the other ones being insulated. The effects of inclination angle and volume fraction showed that the maximum Nusselt number can vary following volume fraction and nanoparticle nature.

Natural convection in a two-dimensional square cavity filled with water-based $\mathrm{CuO}$ nanofluid was studied by Abu-Nada et al. [9]. They considered a vertical walls are hot and cold, from the left to the right respectively. In addition, the upperwall is partially heated by convection. Horizontal surfaces of the enclosure were adiabatic except in the convection zone. They observed that, for low Ra number, heat transfer increases with Biot number and the volume fraction of the nanoparticle. Heat transfer is also enhanced when the length of the convection part of the cavity is increased.

More recently, the natural convection of nanofluids in cavities was investigated from both numerical and experimental approaches in $[10,11,12]$

In the present work we examine the effect of some parameters such as Rayleigh number, inclination angle of inclined walls of the enclosure and the heat source length on the natural convection inside conical container filled with water-Copper nanofluid.

\section{DEFINITION OF CONSIDERED MODEL GOVERNING EQUATIONS}

The continuity, momentum and energy equations for the laminar and steady state natural convection in the two-dimensional enclosure can be written in non-dimensional form using the following non-dimensional parameters:

$$
\begin{aligned}
& \frac{\partial U}{\partial X}+\frac{\partial V}{\partial Y}=0 \\
& U \frac{\partial U}{\partial X}+V \frac{\partial U}{\partial Y}=-\frac{\partial P}{\partial X}+\frac{\mu_{n f}}{\rho_{n f} \alpha_{f}}\left(\frac{\partial^{2} U}{\partial X^{2}}+\frac{\partial^{2} U}{\partial Y^{2}}\right) \\
& U \frac{\partial V}{\partial X}+V \frac{\partial V}{\partial Y}=-\frac{\partial P}{\partial Y}+\frac{\mu_{n f}}{\rho_{n f} \alpha_{f}}\left(\frac{\partial^{2} V}{\partial X^{2}}+\frac{\partial^{2} V}{\partial Y^{2}}\right)+\frac{(\rho \beta)_{n f}}{\rho_{n f} \beta_{f}} R a \operatorname{Pr} \Theta \\
& U \frac{\partial \Theta}{\partial X}+V \frac{\partial \Theta}{\partial Y}=\frac{\alpha_{n f}}{\alpha_{f}}\left(\frac{\partial^{2} \Theta}{\partial X^{2}}+\frac{\partial^{2} \Theta}{\partial Y^{2}}\right)
\end{aligned}
$$

where, the effective density of the nanofluid is given as

$$
\rho_{n f}=(1-\phi) \rho_{f}+\phi \rho_{P}
$$

and $\phi$ is the solid volume fraction of nanoparticles. Thermal diffusivity of the nanofluid is:

$$
\alpha_{n f}=k_{n f} /\left(\rho C_{p}\right)_{n f}
$$

where, the heat capacitance of the nanofluid given is:

$$
\left(\rho C_{p}\right)_{n f}=(1-\phi)\left(\rho C_{p}\right)_{f}+\phi\left(\rho C_{p}\right)_{P}
$$

The thermal expansion coefficient of the nanofluid can be determined by

$$
(\rho \beta)_{n f}=(1-\phi)(\rho \beta)_{f}+\phi(\rho \beta)_{P}
$$

The effective dynamic viscosity of the nanofluid given by Brinkman [10] is: 


$$
\mu_{n f}=\frac{\mu_{f}}{(1-\phi)^{2.5}}
$$

In Equation (6), knf is the thermal conductivity of the nanofluid, which for spherical nanoparticles, according to Maxwell [11], is:

$$
k_{n f}=k_{f}\left[\frac{\left(k_{f}+2 k_{f}\right)-2 \phi\left(k_{f}-k_{p}\right)}{\left(k_{p}+2 k_{f}\right)+\phi\left(k_{f}-k_{p}\right)}\right]
$$

where, $\mathrm{kp}$ is the thermal conductivity of dispersed nanoparticles and $\mathrm{kf}$ is the thermal conductivity of pure fluid.

The boundary conditions, used to solve the equations (1)-(4) are as follows:

$$
\begin{aligned}
& U=V=\Theta=0 \quad X=0,(0 \leq Y \leq 1) \\
& U=V=\Theta=0 \quad X=1,(0 \leq Y \leq 1) \\
& U=V=\frac{\partial \Theta}{\partial Y}=0 \quad Y=0,(0 \leq X \leq 0.3) \\
& U=V=\frac{\partial \Theta}{\partial Y}=-\frac{k_{f}}{k_{n f}} \quad Y=1,(0.3 \leq X \leq 0.7) \\
& U=V=\frac{\partial \Theta}{\partial Y}=0 \quad Y=1,(0 \leq X \leq 0.3) \\
& U=V=\frac{\partial \Theta}{\partial Y}=0 \quad Y=0,(0.7 \leq X \leq 1) \\
& U=V=\Theta=0 \quad Y=1,(1 / 3 \leq X \leq 2 / 3)
\end{aligned}
$$

Table 1. Thermo-physical properties of water and nanoparticle (cu) [4]

\begin{tabular}{|c|c|c|c|c|}
\hline & $\boldsymbol{\rho}(\mathbf{k g m}-3)$ & $\begin{array}{c}\mathbf{C p}(\mathbf{J k g}-1 \mathbf{k}- \\
\mathbf{1})\end{array}$ & $\mathbf{K}(\mathbf{W m}-\mathbf{1 k - 1 )}$ & $\boldsymbol{\beta ( k - 1 )}$ \\
\hline Pure water & 997 & 4179 & 0.613 & $20.10-5$ \\
\hline Copper (cu) & 8933 & 385 & 401 & 1.67 \\
\hline
\end{tabular}

Table 1 shows thermo-physical properties of water and nanoparticle the and the flow geometry is shown in figure 1. 


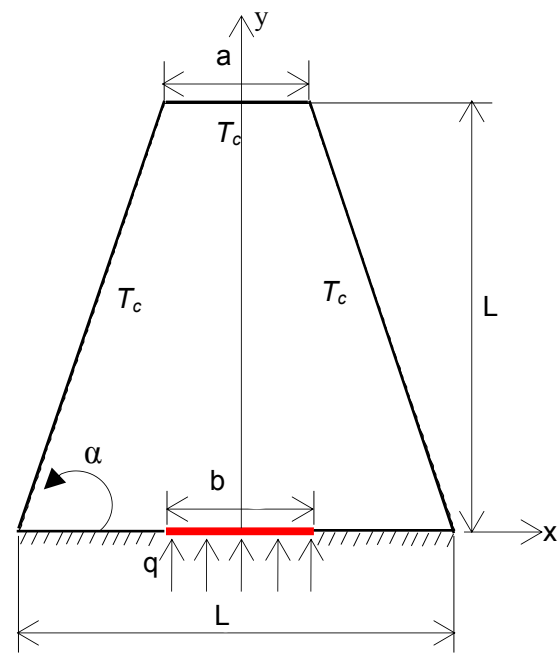

Figure 1. Flow geometry

The local Nusselt number on the heat source surface can be defined as:

where, $\mathrm{h}$ is the convection heat transfer coefficient:

$$
N u=\frac{h L}{k_{f}}
$$

$$
h=\frac{q}{T_{s}-T_{c}}
$$

The dimensionless local Nusselt number:

$$
N u_{s}(X)=\frac{1}{\Theta_{s}(X)}
$$

where, $\Theta_{\mathrm{s}}$ is the dimensionless heat source temperature.

\section{NUMERICAL METHOD}

The governing equations (1)-(4), with the associated boundary conditions, are solved using the finitevolume method. The components of the velocity $(U$ and $V)$ are stored at the staggered locations and the scalar quantities $(\mathrm{P}$ and $\Theta$ ) are stored in the centre of these volumes. The numerical procedure, called SIMPLER [12], is used to handle the pressure-velocity coupling. For treatment of the convection and diffusion terms in equations (2)-(4) central difference scheme is adopted. The discretized algebraic equations are solved by the line-by-line tridiagonale matrix algorithm (TDMA). Convergence at a given time step is declared when the maximum relative change between two consecutive iteration levels fell below than $10^{-5}$, for $U, V$ and $\Theta$. At this stage, the steady state solution is obtained. A parallel test was made to guarantee that the energy balance between the hot and cold walls is less than a prescribed accuracy value, i.e., $0.2 \%$.

\section{RESULTS AND DISCUSSION Validation}

The present numerical result was tested successfully in comparison with the natural convection studies in enclosures developed by Aminossadati and Ghasem [4] for natural convection cooling of a localised heat source at the bottom enclosure filled with $\mathrm{Cu}$-water nanofluid at different Rayleigh numbers (Table 2).

For all simulations, pure water is considered as the base fluid with $\operatorname{Pr}=6.2$ and $(\mathrm{Cu})$ is the nanoparticle. The solid volume fractions of the nanofluid is taken $(\Phi=0.1)$. The effect of Rayleigh number, the heat source heat source length and inclination angle of inclined wall of the enclosure are determined. 
Table 2. Validation of the present results with Aminossadati and Ghasem [4].

\begin{tabular}{|c|c|c|c|c|}
\hline \multicolumn{5}{|c|}{ Rayleigh Number } \\
\hline \multirow{3}{*}{ b=0.2 } & & $10^{4}$ & $10^{5}$ & $10^{6}$ \\
\cline { 2 - 5 } & Present work & 0.1816 & 0.1485 & 0.1042 \\
\cline { 2 - 5 } & $\begin{array}{c}\text { Aminossadati and } \\
\text { Ghasem[4] }\end{array}$ & 0.1815 & 0.1485 & 0.1040 \\
\cline { 2 - 5 } & Error(\%) & 0.03 & 0.0 & 0.04 \\
\hline
\end{tabular}

\section{The cooling performance of the nanofluid}

We consider in this part, an enclosure filled with $\mathrm{Cu}$-water nanofluid with a heat source located in the middle of the bottom wall $(b=0.4 \mathrm{~L})$ and the top of wall length, $a=L / 3$. Figure 2 illustrates the effects of Rayleigh number to streamlines(left) and isotherms(right) for the case of pure water (indices f) and nanofluid (indices nf). In this figure, the heat source is located in the middle of the bottom wall $(b=0.4 \mathrm{~L})$, symmetrical flow and temperature patterns are observed in the enclosure.

For the case of $\mathrm{Ra}=10^{3}$ (Figure 2 top), it is clear that, the addition of nanoparticles to pure water reduces the strength of flow field, this results are observed by other researchers [3-4] and the two counter-rotating rotation cells within the enclosure are intensified. The isotherms indicate that the reduction is more distinct at low Rayleigh numbers where conduction heat transfer dominates. For high Rayleigh numbers the convection heat transfert dominates. It is also apparent that as nanoparticles are added, the maximum dimensionless temperature is reduced which shows the perfection of cooling performance.

The surface temperature of heated surfaces with fixed heat flux is not uniform and has a maximum value where the temperature difference with the adjacent flow is minimal (Figure 3a). At this point, for all Rayleigh numbers, the corresponding Nusselt number is minimum (Figure 3b). Figure 3 shows that the maximum surface temperature of the heat source is reduced by increasing the Rayleigh numbers. This reduction is less evident as the heat transfer mechanism within the enclosure shifts from conduction (low Rayleigh ).

\section{The effects of heat source length}

In this case of the study, the effect of heat source length located in the bottom wall of the conical container is considered. Figure 4 shows the effects of heat source lengths $(b=0.3 \mathrm{~L}, b=0.7 \mathrm{~L}$ and $b=\mathrm{L})$, on the isotherms at $\mathrm{Ra}$ $=10^{3} ; 10^{4}, 10^{5}$ and $10^{6}$. The figures show that as the heat source length increases, the higher temperature patterns are observed. This can be explained by higher heat generation rates as the heat source length increases. Moreover, higher heat generation rates are associated with stronger buoyant forces which intensify the circulating cells. It is also noted that since the heat source remains in the middle of the bottom wall, symmetrical circulating cells are generated regardless of the length of the heat source. The isotherms also have symmetrical shape at each Ra, with a heat source $(b=0.4 \mathrm{~L})$ located in the middle of the bottom wall (Figure 4 left), however, they display different behaviours as Rayleigh number changes. $\mathrm{Ra}=10^{3}$ and $10^{4}$, where conduction dominates the flow regime, the isotherms are distributed near the heat source and tend to be parallel to the heat source. As the Rayleigh number increases, isotherms display more distinguished boundary layers. It is clear that the flow and temperature patterns are influenced by the presence of nanoparticle.

For the cases of the isotherms show that as the heat source length $(b=0.7 \mathrm{~L})$, see Figure 4 (middle), the maximum temperature increases. This can be explained by the distance that the fluid needs to travel in the circulating cell to exchange the heat between the heat source and the left cold wall. In fact, the closer the heat source is to the left cold wall, the higher heat removal and the lower heat source maximum temperature is achieved. Two unsymmetrical circulating cells with unequal strengths are observed when the heat source is located next to the left wall. 
Journal of Thermal Engineering, Research Article, Vol. 4, No. 1, pp. 1713-1723, January, 2018

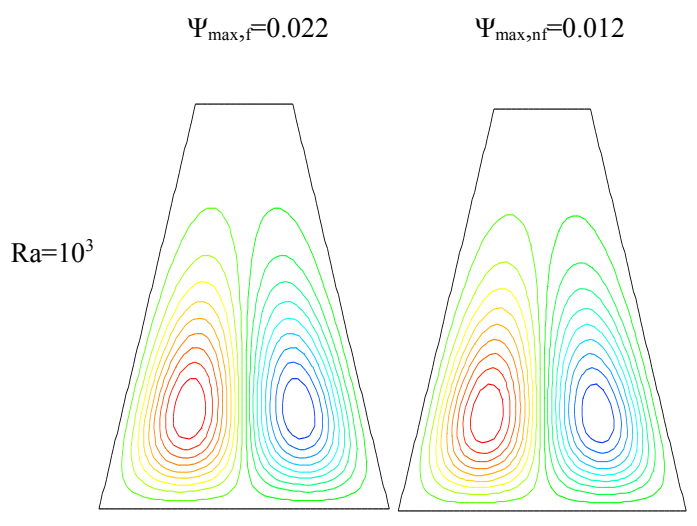

$\Theta_{\text {max }, \mathrm{f}}=0.269 \quad \Theta_{\mathrm{max}, \mathrm{nf}}=0.202$

$\Psi \max , \mathrm{f}=0.0 .24$

$\Psi \max , \mathrm{nf}=0.013$
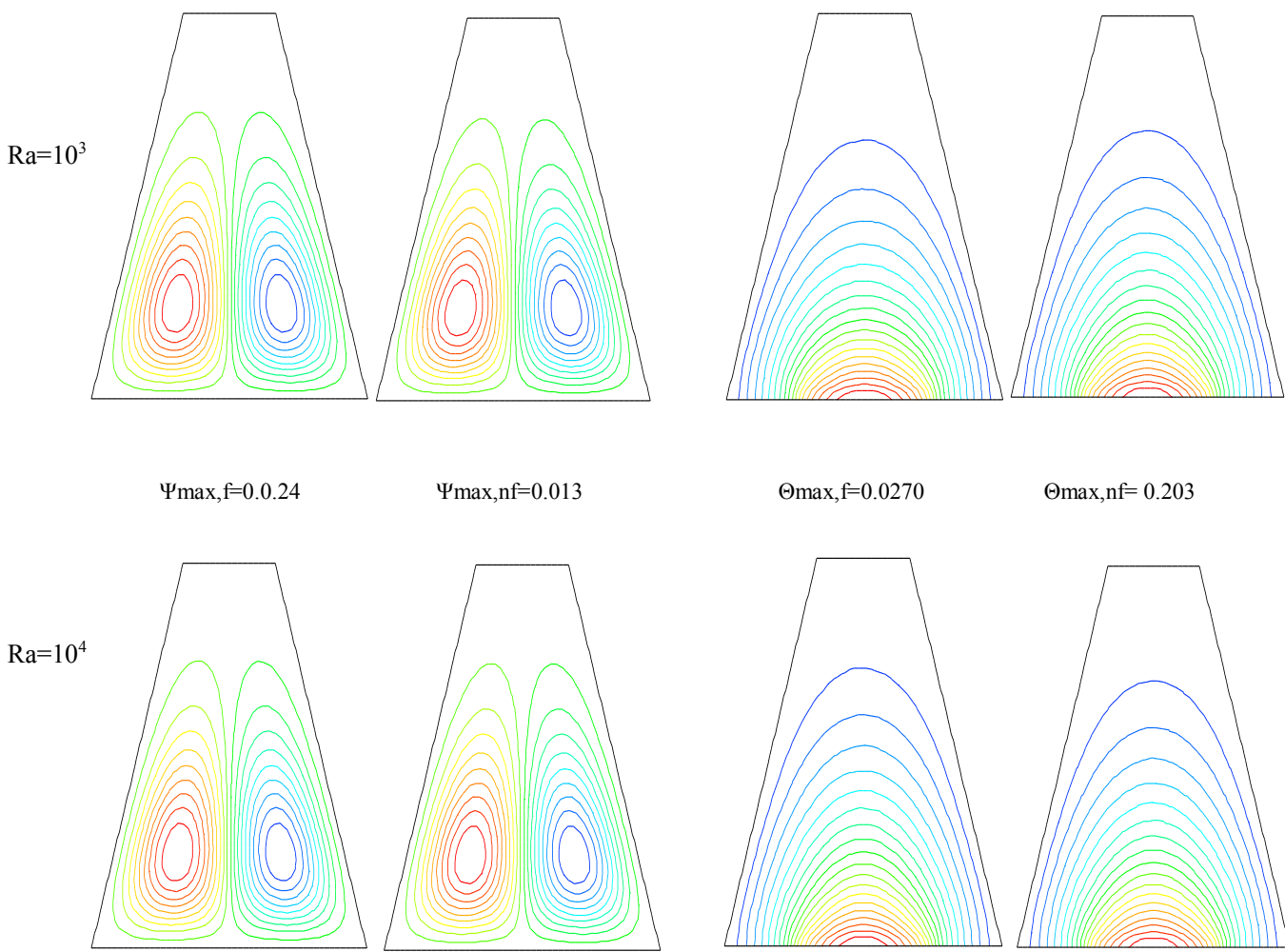

$\Theta \max , \mathrm{f}=0.0270$

$\Theta \max , \mathrm{nf}=0.203$

$\Psi \max , \mathrm{f}=2.6$

$\Psi \max , \mathrm{nf}=1.65$
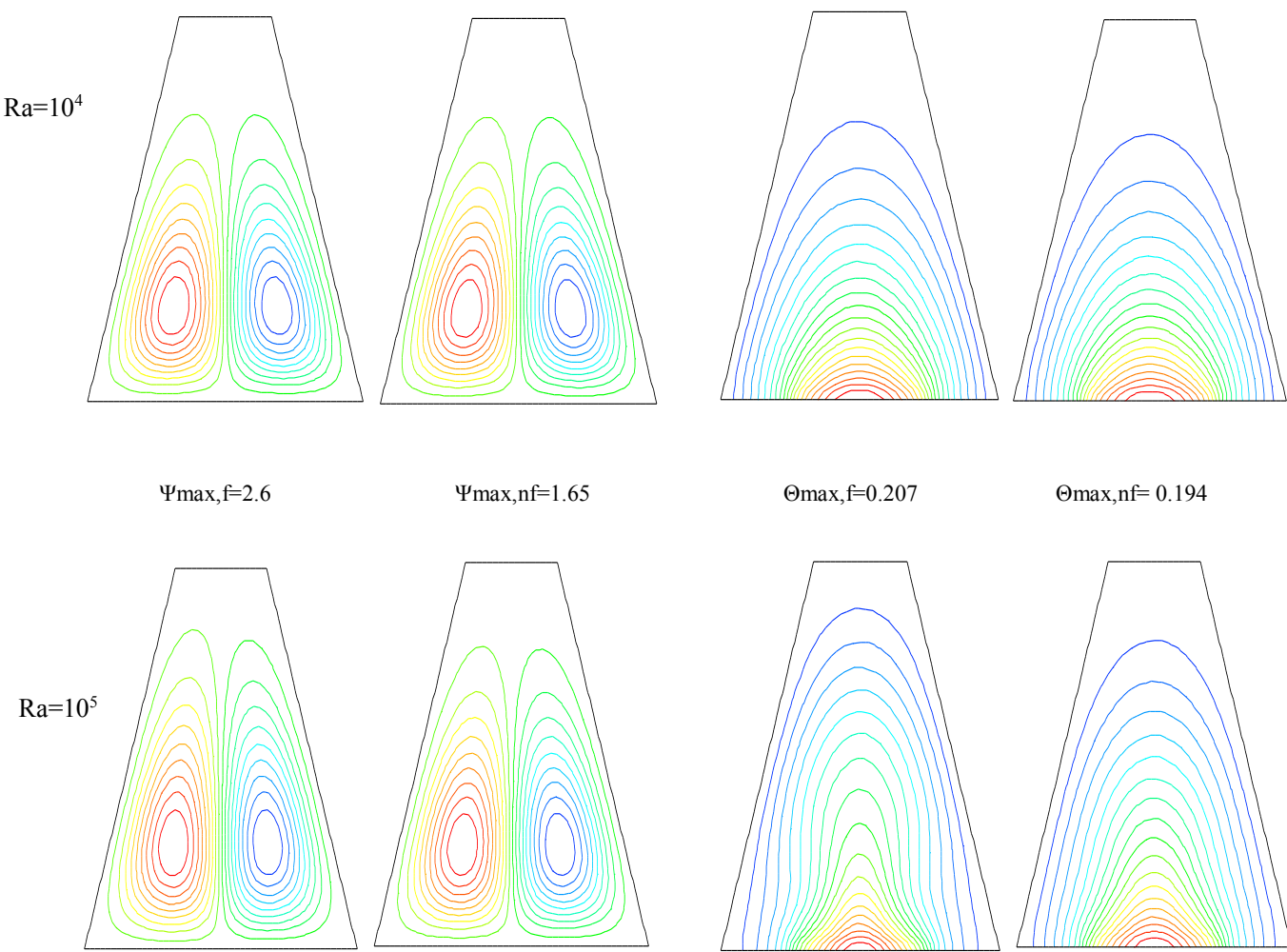

$\Theta \max , \mathrm{f}=0.207$

$\Theta \max , \mathrm{nf}=0.194$

$\Psi_{\max , \mathrm{f}}=9.62$

$\Psi_{\text {max }, n f}=8.30$

$\Theta_{\max , f}=0.116$

$\Theta_{\text {max }, n f}=0.108$
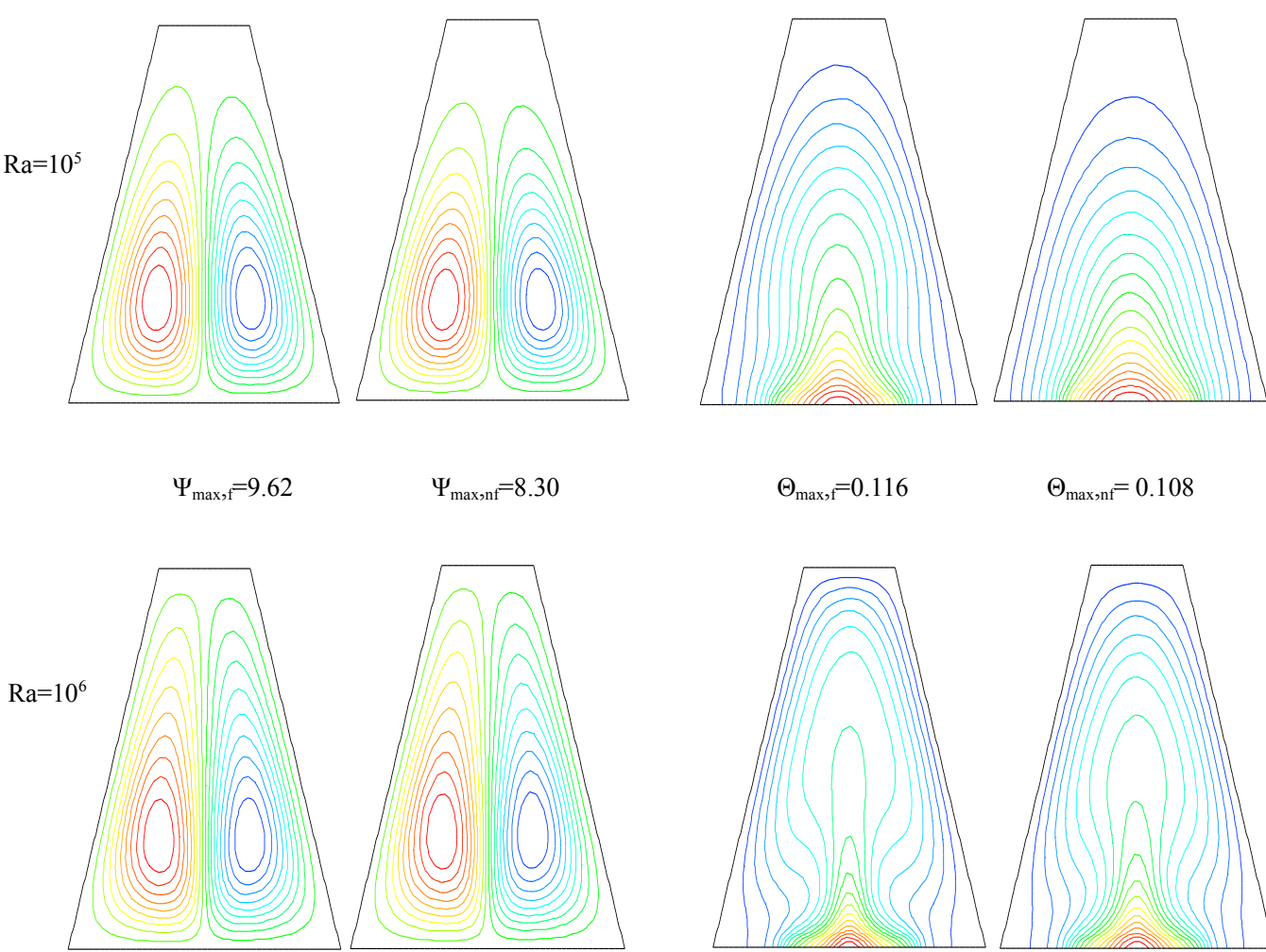

Figure 2. Streamlines (left) and isotherms (right) for the (f) pure water (nf) nanofluid (Cu-water), at different Rayleigh numbers. 


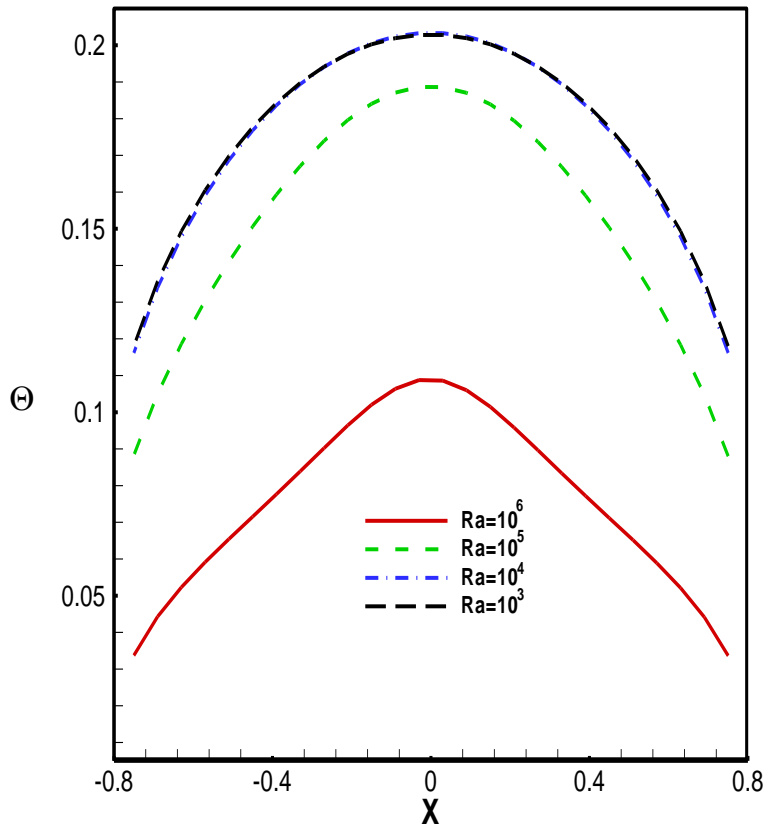

(a)

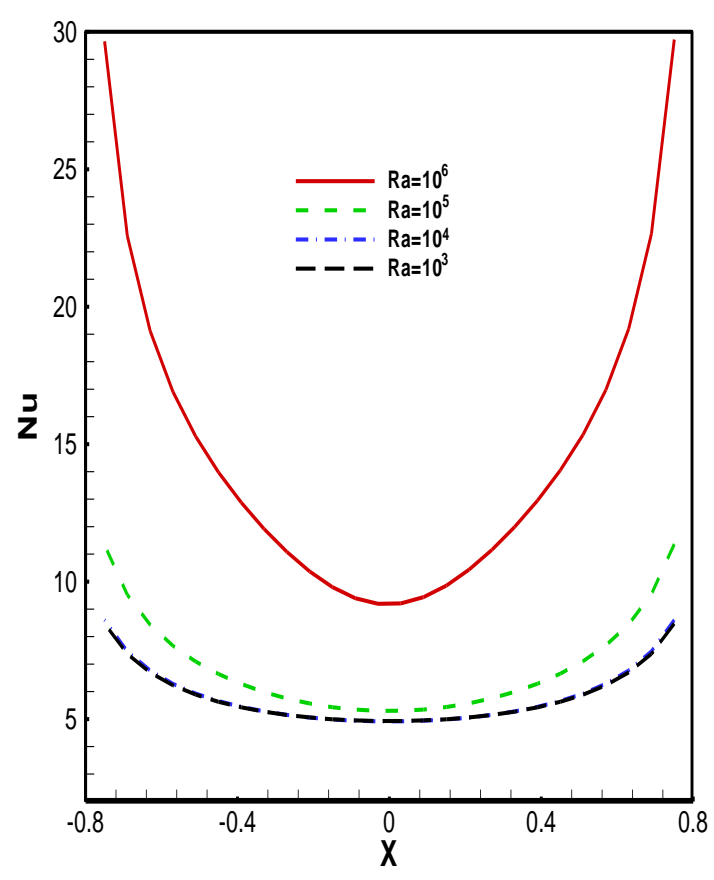

(b)

Figure 3. Case of $b=0.4 \mathrm{~L}$ and $\mathrm{a}=\mathrm{L} / 3$ : a) Profile of local temperature along the heat source for various Rayleigh numbers. (b) Profile of local Nusselt number along the heat source for various for various Rayleigh numbers.

The isotherms show that as the heat source length $(b=\mathrm{L})$, the maximum flow temperature increases further. As is clearly shown in contour plots of isotherms (Figure 4), convective heat transfer dominates the temperature distribution for the cases of $\mathrm{Ra}=10^{5}$ and $10^{6}$. It can be seen that in the convection dominated flow regime, the maximum temperature decreases as Rayleigh number increases due to stronger buoyancy forces. As the length of the heat source increases, the maximum temperature continuously increases due to the higher heat flux generated by the heat source.

\section{The effects of sidewall inclination}

In this part of the study; the effect of sidewall inclination in flow structure and the isotherms for various inclination angle of inclined wall of the enclosure are determined. The main parameter varied in the calculations was the cone angle $\alpha$. Calculations were carried out for tangent $\alpha=2$ (triangle geometry), tangent $\alpha=3$, tangent $\alpha=4$ and $\alpha=90^{\circ}$ ( square geometry) and the limiting case of $b=0.4 \mathrm{~L}$, when the heat source is located in middle bottom wall. For the majority of calculations the Rayleigh number chosen was $10^{4}$ and $10^{5}$. The lower Rayleigh number corresponds to a conduction and convective heat transfer dominates the temperature distribution for the case of Ra $=10^{5}$. As can be seen in Figure 5, the maximum temperature increases with increasing values of $\alpha$ in case of $\mathrm{Ra}=10^{4}$, but it is clear if the Rayleigh number increases until $\mathrm{Ra}=10^{5}$, the maximum temperature decreases.

Figure 6 shows the profile of temperature and local Nusselt number along the heat source for different inclination angle of inclined wall of the encosure. Symmetrical profiles are obtained for Rayleigh number $\left(\mathrm{Ra}=10^{4}\right.$ and $\left.10^{5}\right)$ for the middle of the heat source $(\mathrm{b}=0.4 \mathrm{~L})$. Figure 5 shows that the maximum surface temperature of the heat source is reduced by decreasing the angle of inclined wall, at low Rayleigh numbers. When the heat transfer mechanism convection (high Rayleigh numbers) dominated flow, the maximum surface temperature is increased by decreasing the angle of inclined wall. 
$\mathrm{Ra}=10^{3}$

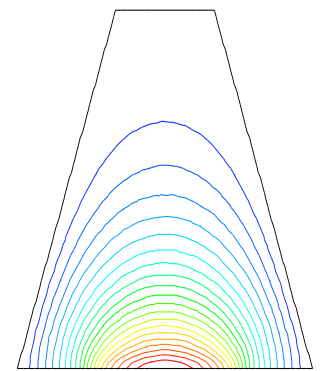

$\Theta_{\text {max }, \mathrm{nf}}=0.202 \quad \Theta_{\text {max }, \mathrm{nf}}=0.222$

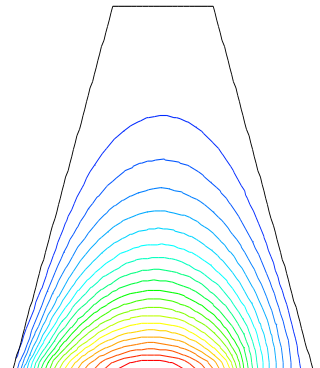

$\Theta_{\max , \mathrm{nf}}=0.239$
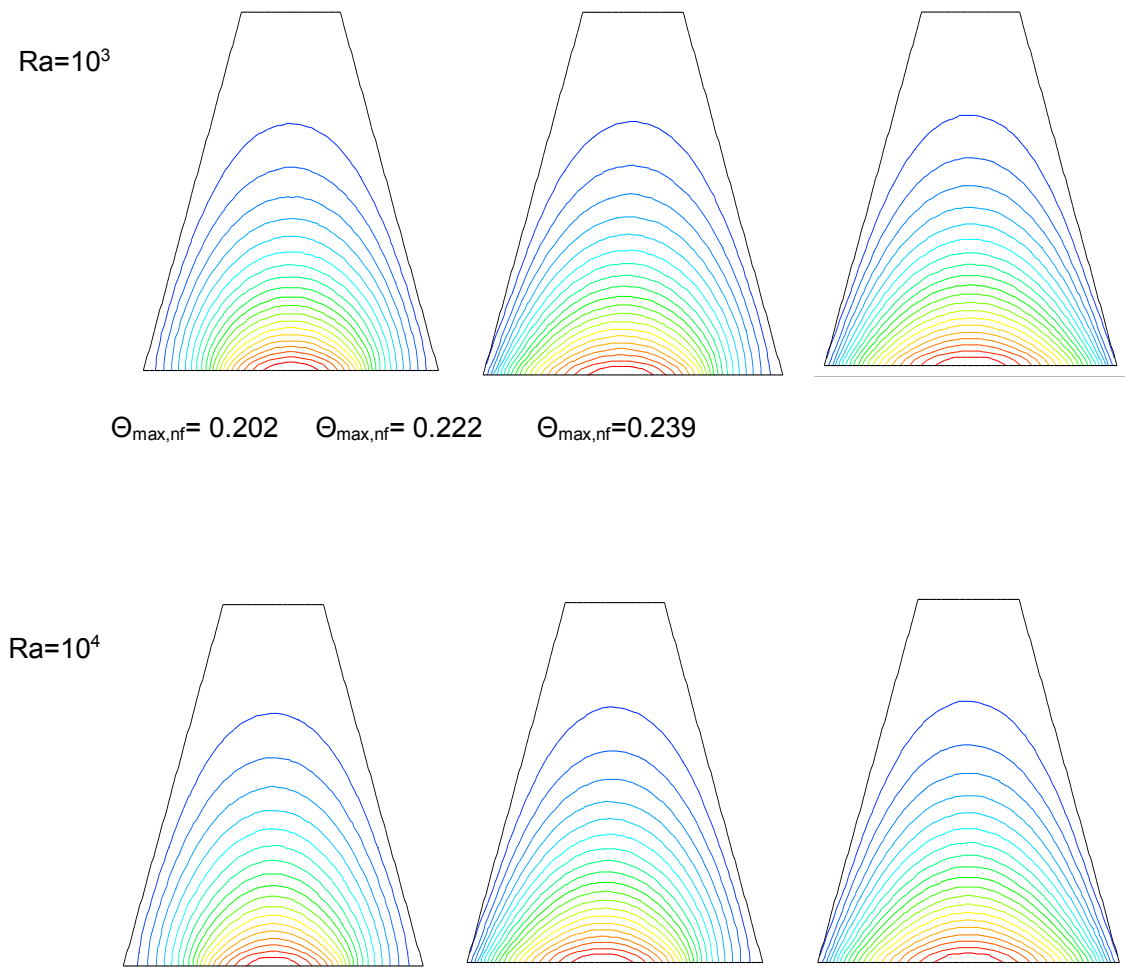

$\Theta_{\max , \mathrm{nf}}=0.204$

$\Theta_{\max , \mathrm{nf}}=0.223$

$\Theta_{\max , \mathrm{nf}}=0.243$

$\mathrm{Ra}=10^{5}$
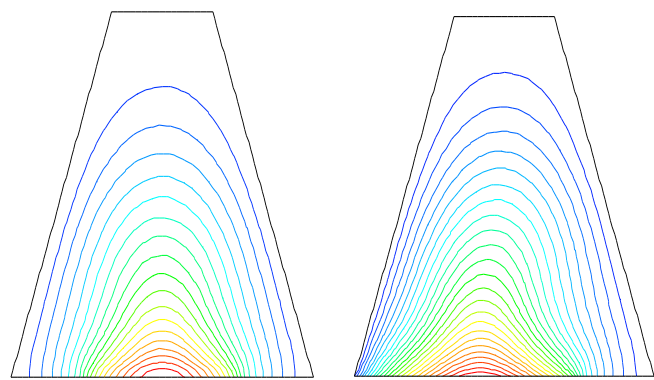

$\Theta_{\max , \mathrm{nf}}=0.211$

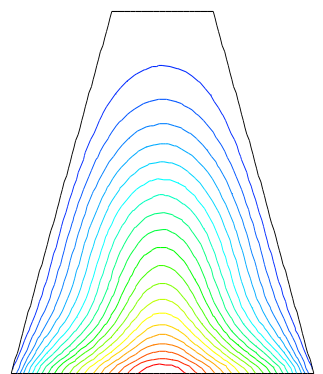

$\Theta_{\max , \mathrm{nf}}=0.189$

$\Theta_{\max , \mathrm{nf}}=0.223$

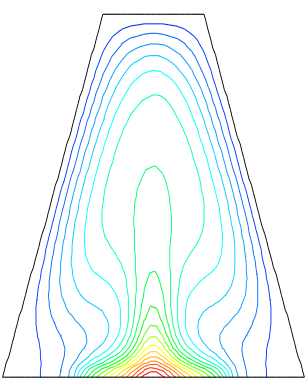

$\Theta_{\max , \mathrm{nf}}=0.114$

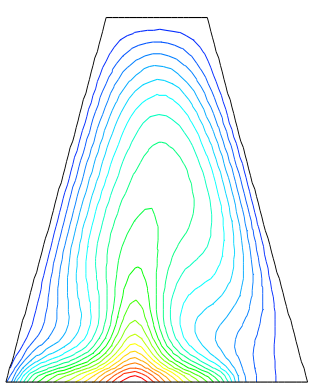

$\Theta_{\max , \mathrm{nf}}=0.121$

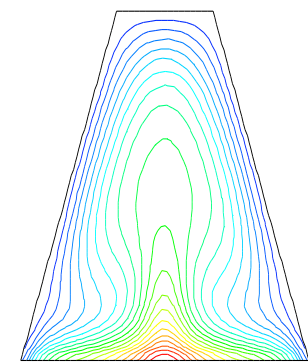

$\Theta_{\max , \mathrm{nf}}=0.130$

Figure 4. Isotherms at different heat source length, $b=0.3 \mathrm{~L}$ (left), $\mathrm{b}=0.7 \mathrm{~L}$ (middle) and $\mathrm{b}=\mathrm{L}$ (right) for the nanofluid $(\mathrm{Cu}-$ water). 


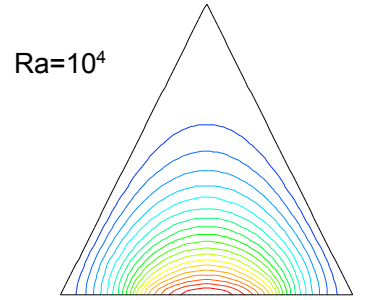

$\Theta_{\max }=0.192$

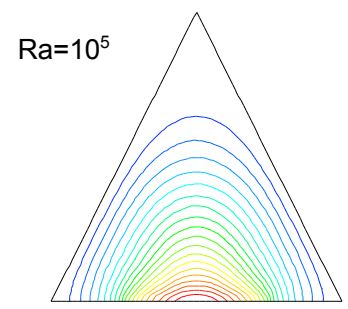

$\Theta_{\max }=0.189$

(a)

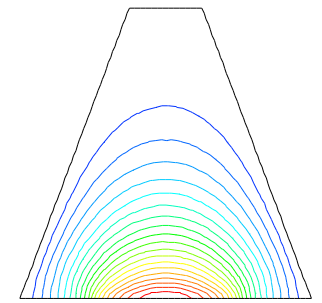

$\Theta_{\max }=0.204$

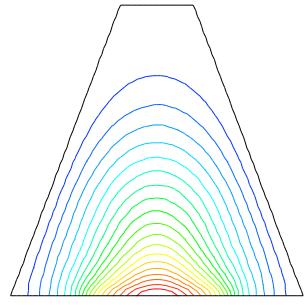

$\Theta_{\max }=0.188$

(b)

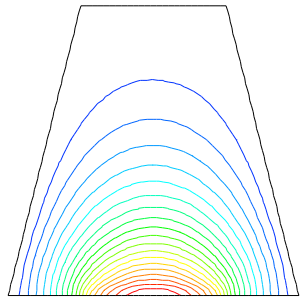

$\Theta_{\max }=0.207$

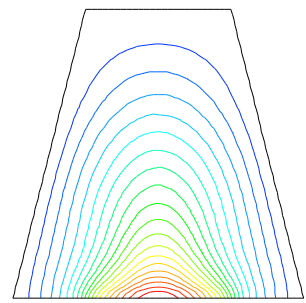

$\Theta_{\max }=0.186$,

(c)

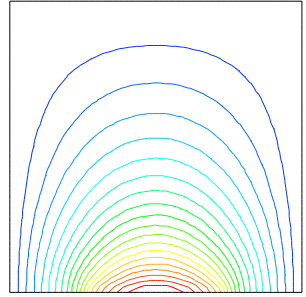

$\Theta_{\max }=0.221$

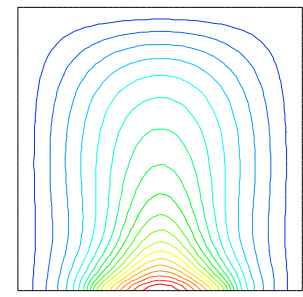

$\Theta_{\max }=0.176$

(d)

Figure 5. Isotherms for geometry with, (a) $\operatorname{tg} \alpha=2$ (b) $\operatorname{tg} \alpha=3$ (c) $\operatorname{tg} \alpha=4$, (d) $\alpha=90^{\circ}$.
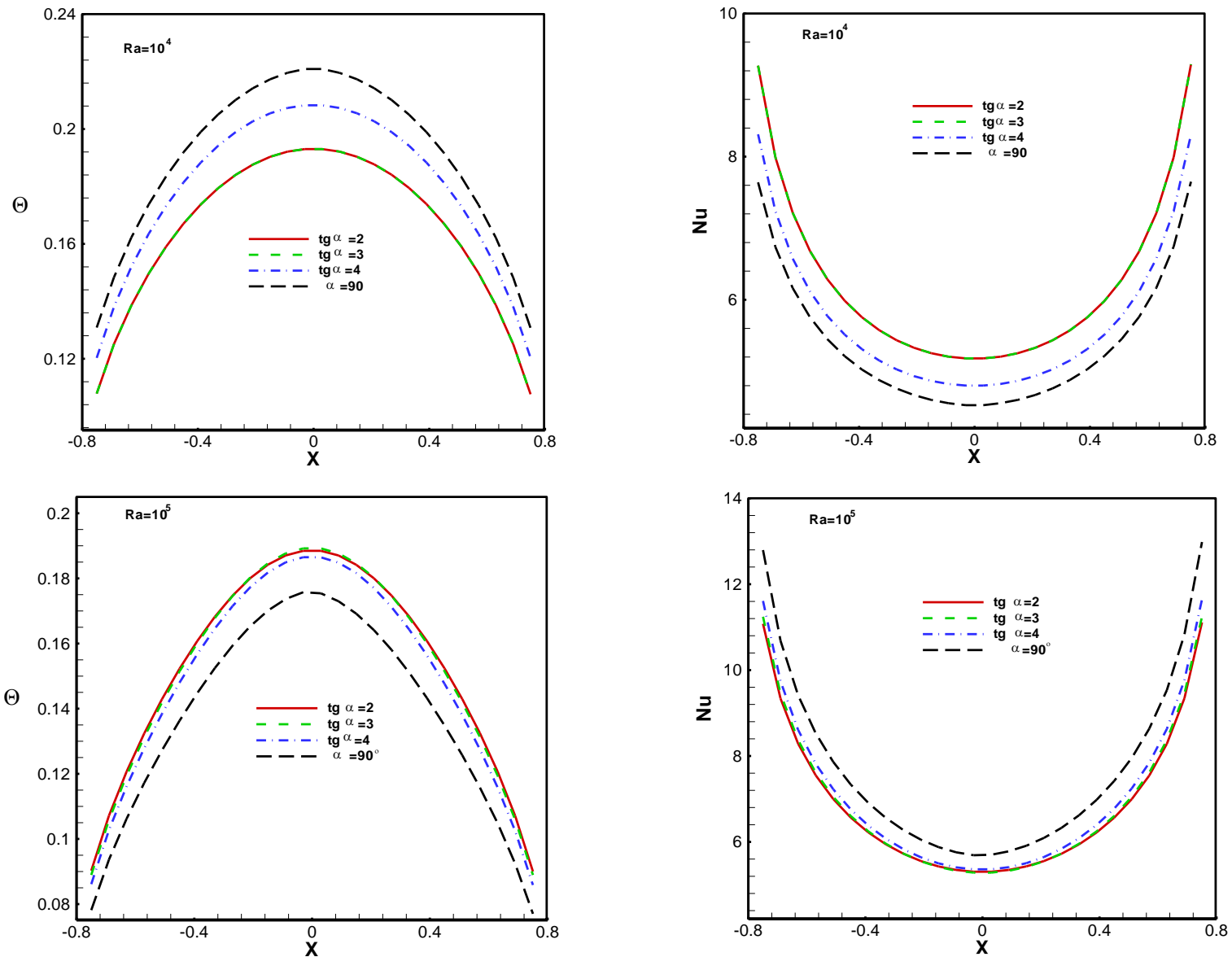

Figure 6. Profile of temperature (left) and local Nusselt number (right) along the heat source for various inclination angle $\alpha$ at $\mathrm{Ra}=10^{4}$ (top) and $\mathrm{Ra}=10^{5}$ (bottom); 


\section{CONCLUSION}

The results of numerical simulation have been presented for the flow generated in a truncated cone filled with nanofluid (water-Cu). The effects of Rayleigh number, heat source length and inclination angle of inclined wall of the enclosure are studied. The finite volume method has been used to numerically solve the transport equations. Our numerical simulations have been presented for various values of the Rayleigh number $\mathrm{Ra}=10^{3}, 10^{4}$, $10^{5}$, and $10^{6}$, and various values of the heat source length $(0.3 \mathrm{~L}, 0.7 \mathrm{~L}$ and $\mathrm{L})$, for various inclination angle $(\operatorname{tg} \alpha=2$, $\operatorname{tg} \alpha=3, \operatorname{tg} \alpha=4$ and $\left.\alpha=90^{\circ}\right)$. The main results obtained in this study are as follows.

- The computer code developed in this study was validated with the results found in the literature, and good agreement has been obtained.

- When the nanoparticles are added, the maximum temperature is reduced which shows the perfection of cooling performance.

- The maximum surface temperature of the heat source is reduced by increasing the Rayleigh numbers.

- The maximum temperature increases with increasing the heat source length.

- A decreasing angle of inclined wall led to the decreasing the maximum temperature, when the heat transfer mechanism conduction dominated flow. The effects were also reversed if the convection dominates the flow regime.

\section{NOMENCLATURE}

a length of top wall, $m$

$\mathrm{b} \quad$ length of heat source, $\mathrm{m}$

$\mathrm{C}_{\mathrm{P}} \quad$ specific heat, $\mathrm{J} \mathrm{kg}^{-1} \mathrm{~K}^{-1}$

g gravitational acceleration, $\mathrm{ms}^{-2}$

$\mathrm{k}$ thermal conductivity, $\mathrm{Wm}^{-1} \mathrm{~K}^{-1}$

$\mathrm{L} \quad$ cavity length, $\mathrm{m}$

$\mathrm{Nu}$ local Nusselt number on the heat source surface

$\bar{p} \quad$ modified pressure $(\mathrm{p}+\rho \mathrm{gy})$

P dimensionless pressure $P=\frac{\bar{p} L^{2}}{\rho_{n f} \partial \alpha_{f}^{2}}$

Pr Prandtl number $\operatorname{Pr}=v_{f} / \alpha_{f}$

q heat generation per area, $\mathrm{W} / \mathrm{m}^{2}$

Ra Rayleigh number $R a=\frac{g \beta f L^{3} \Delta T}{v_{f} \alpha_{f}}$

$\mathrm{T}$ temperature, $\mathrm{K}$

$\mathrm{u}, \mathrm{v} \quad$ velocity components in $\mathrm{x}, \mathrm{y}$ directions, $\mathrm{ms}^{-1}$

$\mathrm{U}, \mathrm{V}$ dimensionless velocity components

$\mathrm{X}, \mathrm{Y}$ dimensionless coordinates $(\mathrm{x} / \mathrm{L}, \mathrm{y} / \mathrm{L})$

$\alpha \quad$ thermal diffusivity, $\mathrm{m}^{2} \mathrm{~s}^{-1}\left(\mathrm{k} / \rho \mathrm{C}_{\mathrm{p}}\right)$

$\beta \quad$ thermal expansion coefficient, $\mathrm{K}^{-1}$

$\Delta \mathrm{T} \quad$ temperature difference $\left(\mathrm{qL} / \mathrm{k}_{f}\right)$

$\Phi \quad$ solid volume fraction

$\Theta \quad$ dimensionless temperature $\left(\mathrm{T}-\mathrm{T}_{\mathrm{c}} / \Delta \mathrm{T}\right)$

$\mu \quad$ Dynamic viscosity, $\mathrm{N} \mathrm{sm}^{-2}$

$v \quad$ kinematic viscosity, $\mathrm{m}^{2} \mathrm{~s}^{-1}(\mu / \rho)$

$\rho$ density, $\mathrm{kgm}^{-3}$

c cold wall

f pure fluid

nf nanofluid 


\section{REFERENCES}

[1] Khanafer, K., Vafai, K., \& Lightstone, M. (2003). Buoyancy-driven heat transfer enhancement in a twodimensional enclosure utilizing nanofluids. International Journal of Heat and Mass Transfer, 46(19), 3639-3653. [2] Jou, R. Y., \& Tzeng, S. C. (2006). Numerical research of nature convective heat transfer enhancement filled with nanofluids in rectangular enclosures. International Communications in Heat and Mass Transfer, 33(6), 727736.

[3] Oztop, H. F., \& Abu-Nada, E. (2008). Numerical study of natural convection in partially heated rectangular enclosures filled with nanofluids. International Journal of Heat and Fluid Flow, 29(5), 1326-1336. [4] Aminossadati, S. M., \& Ghasemi, B. (2009). Natural convection cooling of a localised heat source at the bottom of a nanofluid-filled enclosure. European Journal of Mechanics, B/Fluids, 28(5), 630-640. [5] Ben-Mansour, R., \& Habib, M. A. (2013). Use of nanofluids for improved natural cooling of discretely heated cavities. Advances in Mechanical Engineering, 2013. [6] Sun, Q., \& Pop, I. (2011). Free convection in a triangle cavity filled with a porous medium saturated with nanofluids with flush mounted heater on the wall. International Journal of Thermal Sciences, 50(11), 2141-2153. [7] Garoosi, F., Bagheri, G., \& Talebi, F. (2013). Numerical simulation of natural convection of nanofluids in a square cavity with several pairs of heaters and coolers (HACs) inside. International Journal of Heat and Mass Transfer, 67 , $362-376$. [8] Heris, S. Z., Pour, M. B., Mahian, O., \& Wongwises, S. (2014). A comparative experimental study on the natural convection heat transfer of different metal oxide nanopowders suspended in turbine oil inside an inclined cavity. International Journal of Heat and Mass Transfer, 73, 231-238. [9] Abu-Nada, E., Oztop, H. F., \& Pop, I. (2012). Buoyancy induced flow in a nanofluid filled enclosure partially exposed to forced convection. Superlattices and Microstructures, 51(3), 381-395. [10] Lazarus, G. (2015). Nanofluid heat transfer and applications. Journal of Thermal Engineering, 1(2), 113. [11] Estellé, P., Halelfadl, S., \& Maré, T. (2015). Thermal Conductivity of Cnt Water Based Nanofluids: Experimental Trends and Models Overview. Journal of Thermal Enginnering, 1(2), 381-390. [12] Öztop, H., Selimefendigil F., Abu-Nada E., Al-Salem K., (2016) Recent Developments of Computational Methods on Natural Convection in Curvilinear Shaped Enclosures. Journal of Thermal Engineering, 2 (2), 693 698.

[13] Patankar, S. (1980). Numerical heat transfer and fluid flow. Series in coputational methods in mechanics and thermal sciences. 